\title{
Effect of Curing and Compression Process on the Drug Release of Coated Ion-Exchange Resin Complexes
}

\author{
Seong Hoon Jeong ${ }^{\dagger}$, Hunsik Wang ${ }^{1}$, Jaseong Koo ${ }^{1}$, Eun Joo Choi and Kinam Park \\ Collegel of Pharmacy, Pusan National University, Busan, 609-735, Republic of Korea \\ ${ }^{1}$ Center for nanotechnology-based new drug dosage form, College of Pharmacy, \\ Chungnam National University, Daejeon 305-764, Republic of Korea \\ ${ }^{2}$ Department of Pharmaceutics \& Biomedical Engineering, Purdue University, West Lafayette, IN 47907, U.S.A.
}

(Received March 3, $2011 \cdot$ Revised March 22, $2011 \cdot$ Accepted March 26, 2011)

\begin{abstract}
Ion exchange resins can be one of the good carriers for sustained drug release. However, the sustained release may not be enough only with themselves and hence film coating with rate controlling polymers can be applied to have a further effect on the drug release. Due to the environmental and economic issues of organic solvent for the polymer coating, aqueous polymeric systems were selected to develop dosage forms. Among the many aqueous polymeric dispersions for the film coating, EC (ethylcellulose) based polymers such as Aquacoat ${ }^{\circledR}$ ECD and Surelease ${ }^{\circledR}$ were evaluated. A fluid-bed coating was applied as a processing method. The drug release rate was quite dependent on the coating level so the release rate could be modified easily by changing different levels of the coating. The drug release rate in the Aquacoat $^{\circledR}$ coated resin particles was strongly dependent on curing, which is a thermal treatment to make homogeneous films and circumvent drug release changes during storage. After dissolution test using the compressed tablets in which the coated resin particles are contained, inhomogeneous coating and even pores could be observed showing that the mechanical properties of EC were not resistant to granulation and compaction process. However, when tablets were prepared in different batches, the release profiles were almost identical showing the feasibility of the coated resin particle as incorporated into the tablet formulation.
\end{abstract}

Key words - Ethylcellulose, Ion exchange resin, Curing, Coating, Fluid-bed

Film coating of pharmaceutical dosage forms including tablets, pellets, granules, and even drug crystals has been widely used for the purpose of improving aesthetic qualities of a dosage form, masking unpleasant taste, reducing swallowing problems, improving product stability, and modifying drug release properties. Especially small particle coating such as pellets and beads can offer a couple of advantages compared to coated tablets (Bodmeier, 1997; Ghebre-Sellassie, 1994). The coated small particles are often called multiparticulates, multiple unit extended release dosage forms. The multiparticulates can spread uniformly throughout the gastrointestinal (GI) tract so that they can have less variability of bioavailability and reduced risk of local irritation.

There are mainly three methods of film coating: polymeric solution, aqueous polymeric dispersion, and molten materials. The solvents of polymer solution can be water and any organic solvents depending on the physicochemical properties of the polymers. For example, methylcellulose (MC) and hydrox-

${ }^{\dagger}$ Corresponding Author :

Tel : +82-51-510-2812, E-mail : shjeong@pusan.ac.kr

DOI : 10.4333/KPS.2011.41.2.067 ypropyl methylcellulose (HPMC) are water soluble. They are not for sustained release but for other applications such as taste-masking and layering of colors. One of the limitations would be high viscosity of the polymer solution so the concentration should be adjusted to be handled in the film coating process. In the case of organic solvents, they are expensive compared to water and also cause high cost in solvent recovery. Moreover, they are toxic to workers and environments and also explosive so it is required to keep well-controlled working system (Nagai et al., 1997).

Due to the limitations of organic solvent-based polymer solutions, aqueous polymeric systems have been developed. The widely used aqueous polymeric dispersions, especially for sustained drug release applications are ethylcellulose (EC) based (Aquacoat ${ }^{\circledR}$ ECD and Surelease ${ }^{\circledR}$ ), acrylate based, and vinyl based products. The film formation is dependent on many properties of the polymer systems including viscosity, molecular structure, molecular weight, molecular weight distribution, and film modifiers.

The film coating polymers are mostly amorphous so glass transition temperature $\left(\mathrm{T}_{\mathrm{g}}\right)$ has a significant effect in the formation of the film and its properties. Many polymers used in 
the film coatings have high $T_{\mathrm{g}}$ so plasticizers are usually added to lower the $\mathrm{T}_{\mathrm{g}}$ offering film flexibility (Wheatley and Steuernagel, 1997). The plasticizers can reduce the cohesive intermolecular forces along the polymer chains resulting in reduced tensile strength and $\mathrm{T}_{\mathrm{g}}$, and increased elongation and flexibility of the polymer. With aqueous colloidal polymeric dispersions, the plasticizers are necessary to make minimum film formation temperature (MFT) lower than the coating temperature. The plasticizers can soften the polymeric particles and promote particle deformation and coalescence into a homogeneous film (Bodmeier and Paeratakul, 1997).

Without the polymer coating, drug release rate of ionexchange resins can be modified depending on functional groups, ion exchange capacity, degrees of crosslinking, particle size, and swelling of the resins. However, the release rate of the resin complex may not be satisfactory for sustained release so the resin particles can be coated further to control the release rate by applying a permeable membrane with more flexibility (Atyabi et al., 1996; Bhaskar et al., 1986; Langer, 1993; Motycka and Nairn, 1978). Therefore, drug release can be controlled by combination of diffusion resistance of the core (resin complex), diffusion resistance of the coating, and ion-exchange reaction rate, exhibiting complex release mechanisms.

For the purpose of fast disintegrating tablet development, the coated particles can be compressed with decent tablet excipients using suitable manufacturing processes. If not compressed, the mechanical strength of the coating is not a big concern because burst effect or loss of sustained release might not occur. For example, the coated particles can be filled into hard gelatin capsules. However, the manufacturing cost of the capsules is much higher than that of tablets and also the market trend seems to move to compressed tablets.

The compressed tablets containing coated resin particles should disintegrate quickly into individual particles in the oral cavity. The coated particles should not fuse into a matrix during compression. Moreover, the drug release rate should not be affected by the compaction process. The polymer films should be elastic so that there is no rupture during compression (Dashevsky et al., 2004). Therefore, the mechanical properties of the coating films are very important for successful formulation development. Besides the permeability properties of the coating polymers governing the release rate, the mechanical properties of the coating have to be considered to examine their suitability for the coating of resin particles to be compressed into tablet dosage forms.

The objective of this study was to investigate the usefulness of the aqueous colloidal EC dispersions (Aquacoat ${ }^{\circledR}$ and Sure- lease $^{\circledR}$ ) for the coating of ion-exchange resin complexes and their incorporation into fast disintegrating tablets. Several factors influenced the drug release rate from coated resin particles including granulation and compaction processes. In this study, the post-thermal treatment was also examined for the coated resin particles.

\section{Materials and Methods}

\section{Materials}

An ion-exchange resin (Amberlite ${ }^{\circledR}$ IRP69, polystyrene sulfonate, $\mathrm{Na}^{+}$form, crosslinkage $8 \%$ ) was purchased from Sigma-Aldrich (Sigma-Aldrich Inc., St. Louis, MO). It was purified by rinsing $200 \mathrm{~g}$ of wet resin three times with 1000 $\mathrm{mL}$ of distilled water, twice with $95 \%$ ethanol, and then twice with $1000 \mathrm{~mL}$ of distilled water to remove the ethanol. Each treatment took at least 8 hours by a batch process. After filtration, the resin was dried in a $45^{\circ} \mathrm{C}$ oven, and the moisture content was evaluated using a Karl Fischer titrator (Model 270, Denver Instrument, Arvada, CO). Dextromethorphan hydrobromide monohydrate (DM), a model drug, was obtained from Spectrum $^{\circledR}$ (Spectrum Chemical Mfg. Corp., New Brunswick, NJ). Ethylcellulose (EC) aqueous dispersions of Aquacoat ${ }^{\circledR}$ ECD and Surelease ${ }^{\circledR}$ were donated by FMC BioPolymer (Newark, DE) and Colorcon (West Point, PA), respectively. Table I shows the components and solid contents of the EC aqueous dispersions.

\section{Preparation of DM-loaded resin complexes}

The DM-Amberlite ${ }^{\circledR}$ complex was prepared by a single batch process. The purified ion-exchange resin particles were sieved using Rotap RX-29 (Mentor, OH) to divide the particle size into $106 \sim 150 \mu \mathrm{m}, 75 \sim 106 \mu \mathrm{m}$, and $<38 \mu \mathrm{m}$. The particles of $106 \sim 150 \mu \mathrm{m}$ size were dispersed in a $1.9 \mathrm{w} / \mathrm{v} \%$ of the drug solution with the ratio of 1:1 under magnetic stirring at room temperature for 24 hours. For the determination of equilibrium

Table 1. Components and solid contents of Aquacoat ${ }^{\circledR} E C D$ and Surelease ${ }^{\circledR}$

\begin{tabular}{clcc}
\hline \hline EC dispersions & Components & Contents (\%) & Total solids \\
\hline Aquacoat $^{\circledR}$ ECD & Ethylcellulose & $24.5 \sim 29.5$ & $30 \%$ \\
& Cetyl Alcohol & $1.7 \sim 3.3$ & \\
& Sodium Lauryl & $0.9 \sim 1.7$ & \\
& Sulfate & & \\
Surelease $^{\circledR}$ & Ethylcellulose & NA & $25 \%$ \\
& Oleic Acid & NA & \\
& Dibutyl sebacate & NA & \\
\hline
\end{tabular}


rate, small amount of supernatant was collected with predetermined time intervals to monitor the change of DM concentration in the solution. The collected samples were filtered and diluted before injection into HPLC. The complex was separated by filtration, washed with water, and then dried in an oven.

\section{Preparation of polymer coated resin complexes}

The DM-loaded resin complexes were coated with Aquacoat $^{\circledR}$ ECD or Surelease ${ }^{\circledR}$ in a fluidized-bed coater, MFL-01 (Vector Corporation, Marion, IA) to obtain a predetermined weight gain. Bottom spray coating method (Wurster process) was applied for this process. The dried resin complex (40 g) was mixed with micronized talc $(0.8 \mathrm{~g})$ to improve the initial flowability before the coating process. The coating solution was diluted to $10.0 \mathrm{w} / \mathrm{w} \%$ solid content. In order to enhance the film formation and the flexibility of the films, plasticizer (triethyl citrate) was added to Aquacoat ${ }^{\circledR}$ ECD. Formulations of the coating solution and operating conditions of the fluidbed coater are shown in Table II. The percentage of coating was the applied amount of coating compared to the amount of core (resin complex).

\section{Granulation and compression procedures}

\section{Granulation procedure}

High shear granulation method was applied to prepare the granules containing the coated resin particles (Fu et al., 2005). Table III shows the formulations of the granules. The amount of DM in each formulation was $60 \mathrm{mg}$. Mannogem ${ }^{\mathrm{TM}} \mathrm{EZ}$ Spray, fructose, coated particles, cherry flavor, citric acid and aspartame were weighed as listed in the Table III. The weighed materials were put into a granulation bowl and then mixed on dry state for 1 minute. The granulator settings were mixer speed $400 \mathrm{rpm}$ and chopper speed $300 \mathrm{rpm}$.

$50 \%$ sucrose in EtOH solution (28 g) was transferred into the graduated cylinder. After turning on the granulator, the sucrose solution was poured and mixed for 30 seconds. The granulator settings were changed as follows: mixer speed 900 rpm and chopper speed $100 \mathrm{rpm}$. The wet mass was sieved using Fitz-Sieve with $4 \mathrm{~mm}$ round-hole sieve screen, a $1.5 \mathrm{~mm}$ clearance, and a $500 \mathrm{rpm}$ sieve speed.

The collected wet granules were spread evenly on trays and then placed on drying racks in a drying room $\left(27^{\circ} \mathrm{C}\right.$ and $30 \%$ $\mathrm{RH})$. If the moisture content of the granules was $1.6 \sim 1.9 \%$, then proceeded to dry sieving. If not, continued drying until they reached the target moisture content window. The FitzSieve was used for sieving the dried granules with the $3 \mathrm{~mm}$ round-hole sieve screen, a $0.1 \mathrm{~mm}$ clearance, and a $1200 \mathrm{rpm}$
Table II. Operating conditions and formulation for the preparation of coated resin particles

\begin{tabular}{lcc}
\hline \hline \multicolumn{1}{c}{ Conditions } & Aquacoat $^{\circledR}$ ECD & Surelease ${ }^{\circledR}$ \\
\hline Operating conditions & & \\
Inlet air flow $(\mathrm{L} / \mathrm{m})$ & 45.0 & 43.0 \\
Inlet air temperature $\left({ }^{\circ} \mathrm{C}\right)$ & 80.0 & 80.0 \\
Exhaust temperature $\left({ }^{\circ} \mathrm{C}\right)$ & 27.5 & 26.7 \\
Nozzle pressure $(\mathrm{psi})$ & 15.8 & 15.6 \\
Pump speed $(\mathrm{rpm})$ & 9.0 & 10.0 \\
Formulation & & \\
Aquacoat ${ }^{\circledR} \mathrm{ECD}(\mathrm{g})$ & 24.23 & - \\
Surelease ${ }^{\circledR}(\mathrm{g})$ & - & 40.0 \\
HPMC $(\mathrm{g})$ & 0.93 & - \\
Triethyl citrate $(\mathrm{g})$ & 1.80 & - \\
Water $(\mathrm{g})$ & 73.04 & 60.0 \\
\hline
\end{tabular}

Table III. Components for the granulation process

\begin{tabular}{clc}
\hline \hline Item No. & \multicolumn{1}{c}{ Components } & Weight $(\mathrm{g})$ \\
\hline 1 & Mannogem EZ Spray (mannitol) & 48.8 \\
2 & Advantose FS 95 (Fructose) & 5.0 \\
3 & Coated particles & 29.4 \\
4 & Cherry flavor & 0.3 \\
5 & Citric Acid & 0.5 \\
6 & Aspartame & 2.0 \\
7 & Sugar & 14.0 \\
\hline
\end{tabular}

sieve speed. The collected granules were stored in a plastic bag.

\section{Blending and compression procedures}

Three different types of lubricants were added into the above granules. For the lubricant blending, the pre-measured granules and a lubricant, sodium stearyl fumarate $\left(\mathrm{PRUV}^{\circledR}\right)$ 0.5\% each, were added into a bin blender. Blend time and speed were 15 min and $25 \mathrm{rpm}$, respectively. Tablets of $500 \mathrm{mg}$ were compressed on a single punch Carver Laboratory Press (Carver Inc., Wabash, IN) using plane-face punches with diameter of 0.5 inch.

\section{Drug release test}

The drug release test was conducted according to USP 27 Apparatus 2 guidelines (paddle method) (Vankel ${ }^{\circledR}$ VK 7000, Vankel, Edison, NJ) with $900 \mathrm{~mL}$ dissolution medium maintained at $37 \pm 0.5^{\circ} \mathrm{C}$ and mixed at $100 \mathrm{rpm}$. The dissolution media used in this study were $0.1 \mathrm{M} \mathrm{HCl}(\mathrm{pH}=1.1 \sim 1.2)$. Samples were withdrawn at predetermined time intervals and 
analyzed for drug content using HPLC system (Agilent 1100 Series, Agilent Technologies, Waldbronn, Germany) at a wavelength of $280 \mathrm{~nm}$. Samples were filtered with $0.2 \mu \mathrm{m}$ nylon filters, and then $20 \mu \mathrm{L}$ of the sample was injected. The column used for the analysis was a Symmetry ${ }^{\circledR} \mathrm{C}_{18} 5 \mu \mathrm{m}$ (3.9 $\times 150 \mathrm{~mm}$ ) (Waters Corporation, Milford, MA) with Sentry ${ }^{\mathrm{TM}}$ guard column (Symmetry ${ }^{\circledR} \mathrm{C}_{18} 5 \mu \mathrm{m}, 3.9 \times 20 \mathrm{~mm}$ ). The mobile phase contained a mixture of aqueous buffer $\left(10 \mathrm{mM} \mathrm{KH}_{2} \mathrm{PO}_{4}\right.$ adjusted to $\mathrm{pH} 2.6$ with phosphoric acid) and acetonitrile in a volume ratio of 26:74. The retention time of DM was $3.1 \mathrm{~min}-$ utes and every standard calibration curve was made before analysis to monitor the linearity.

\section{Scanning electron microscopy (SEM)}

The morphologies of DM-loaded resin complexes and coated resin particles were examined by the SEM. Dried samples were attached to specimen stubs using double-sided copper tape and sputter coated with gold-palladium in the presence of argon gas using a Hummer I sputter coater (Anatech Ltd., Denver, NC). The samples were imaged with a JEOL JSM-840 scanning electron microscope (JEOL USA Inc., Peabody, MA) using $5 \mathrm{kV}$ accelerating voltage, 26 28 $\mathrm{mm}$ working distance, and probe current of $3 \times 10^{-11}$ amps.

\section{Results and Discussion}

\section{Effect of curing on the drug release from Aquacoat ${ }^{\circledR}$ coated resin particles}

Curing, also called as a thermal treatment, is a process of storing the coated particles at elevated temperature for short periods. In order to make homogeneous films and circumvent drug release changes during storage, curing is usually recommended (Wesseling and Bodmeier, 2001). It can accelerate the coalescence of the polymer particles, which are not coalesced completely right after the coating. During the curing, the coated particles are subjected to a heat treatment above the $\mathrm{T}_{\mathrm{g}}$ of the polymer. This can be achieved by storing the coated particles in an oven or fluidized bed in high temperature after the complete coating. In this study, high temperature oven $\left(60^{\circ} \mathrm{C}\right)$ was used for the process and the temperature was selected based on the recommendation of the raw material supplier. As shown in the Figure 1, drug release was strongly dependent on the curing process and time. There is a significant difference in drug release rate between the uncured and cured ones. However, the reduction in drug release approached the limiting pattern as the curing time increased. Based on the data, 4 hours of curing at $60^{\circ} \mathrm{C}$ might be enough to achieve the limiting drug release pattern.

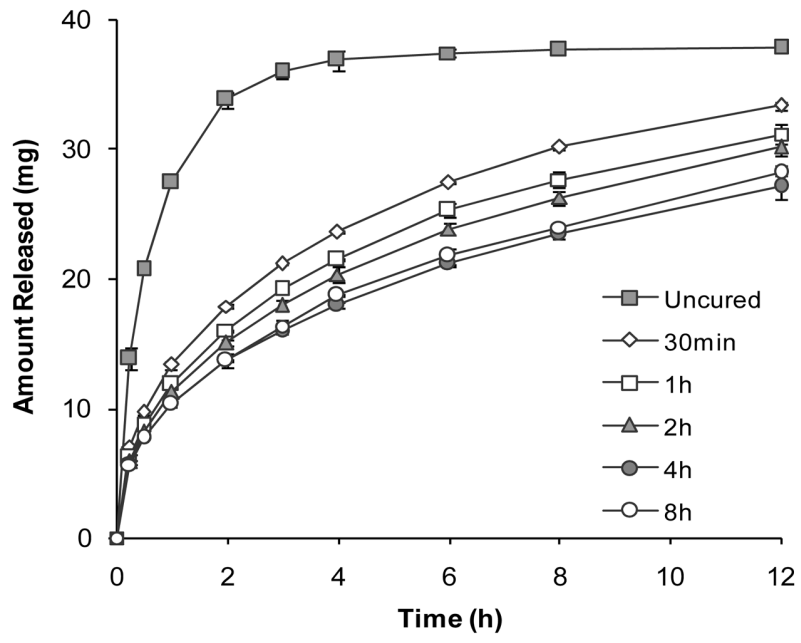

Figure 1. Effect of curing time at $60^{\circ} \mathrm{C}$ on in-vitro $\mathrm{DM}$ release from Aquacoat ${ }^{\circledR}$ coated resin particles in simulated gastric fluid $(\mathrm{pH}=1.2)$ at $37^{\circ} \mathrm{C}$.
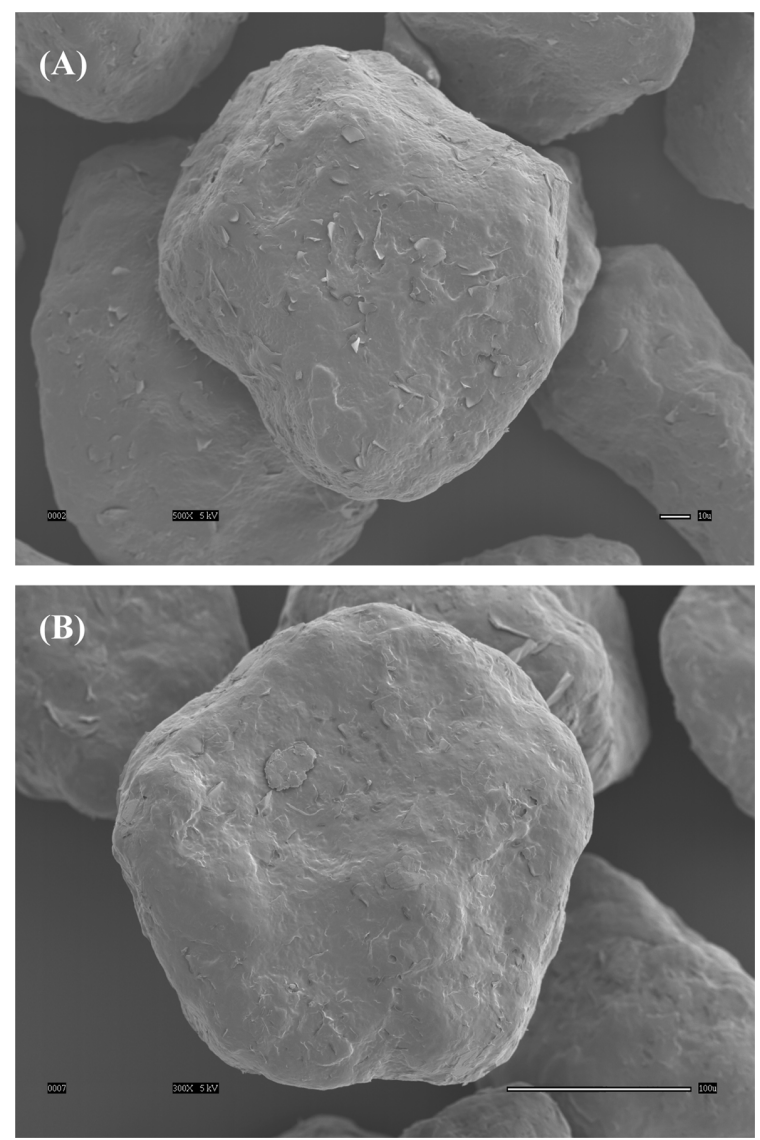

Figure 2. Scanning electron micrographs of Aquacoat ${ }^{\circledR}$ coated resin particles: top (A) is uncured and bottom (B) is cured particles for 8 hours.

Figure 2 shows the SEM pictures of Aquacoat ${ }^{\circledR}$ coated resin particles before and after curing. Before curing (A), surface of the particles was not smooth and looked like there were a lot 
of scales. This might explain the fast drug release rate. However, after curing, the surface became smooth and continuous as shown in Figure 2 (B) indicating the coating polymer was coalesced better than uncured ones.

\section{Effect of granulation and compression processes on the drug release}

The granulation and compaction processes of the coated particles are quite challenging area. Most studies have been focused on the effect of compaction using pellets coated with polymers. For example, EC showed film damage of the coated pellets with a loss of the extended release properties after compaction. Moreover, at higher compression pressures, the pellets were fractured and then fused resulting in a slight decrease in drug release when compared to the release of compacts compressed at lower compression pressures. The compacted resin particles should disintegrate rapidly into individual particles in the oral cavity or GI tract and retain its sustained release properties after the granulation and compaction process.

\section{Aquacoat ${ }^{\circledR}$ coating}

As shown in Figure 3, granulation and compression process affected drug release rate. The both processes caused film damage during the processes causing change in drug release rate. The effect of the rate change was significant for granulation than that of compression. This might be due to the low compression pressure for the tablet compaction. If the compression pressure increased, the release rate might be increased. Figure 4 (A) shows the SEM picture of the com-

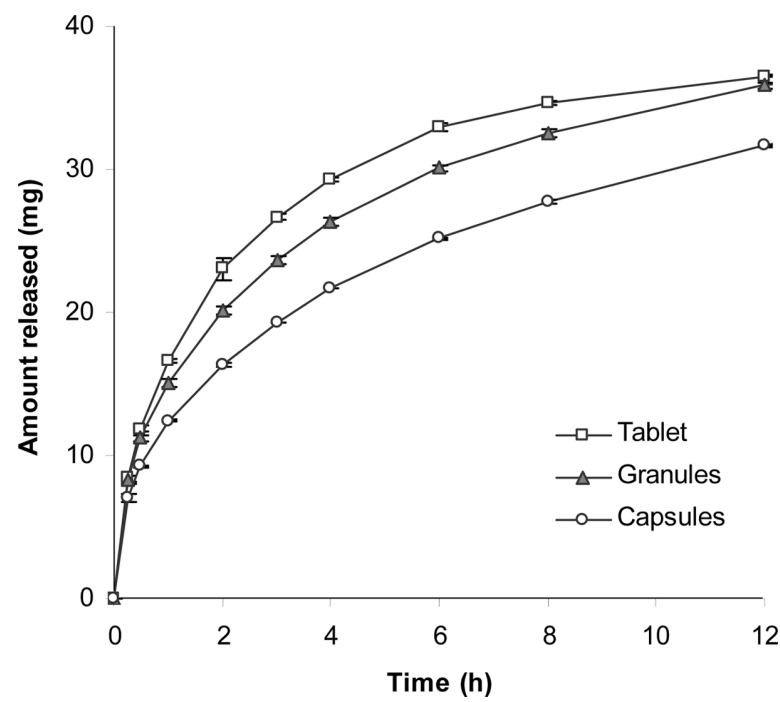

Figure 3. In-vitro release of DM from the coated capsules, granules, and tablets in simulated gastric fluid $(\mathrm{pH}=1.2)$ at $37^{\circ} \mathrm{C}$. Granules and tablets have the same amount of coated capsules to make the same amount of DM in the formulation.
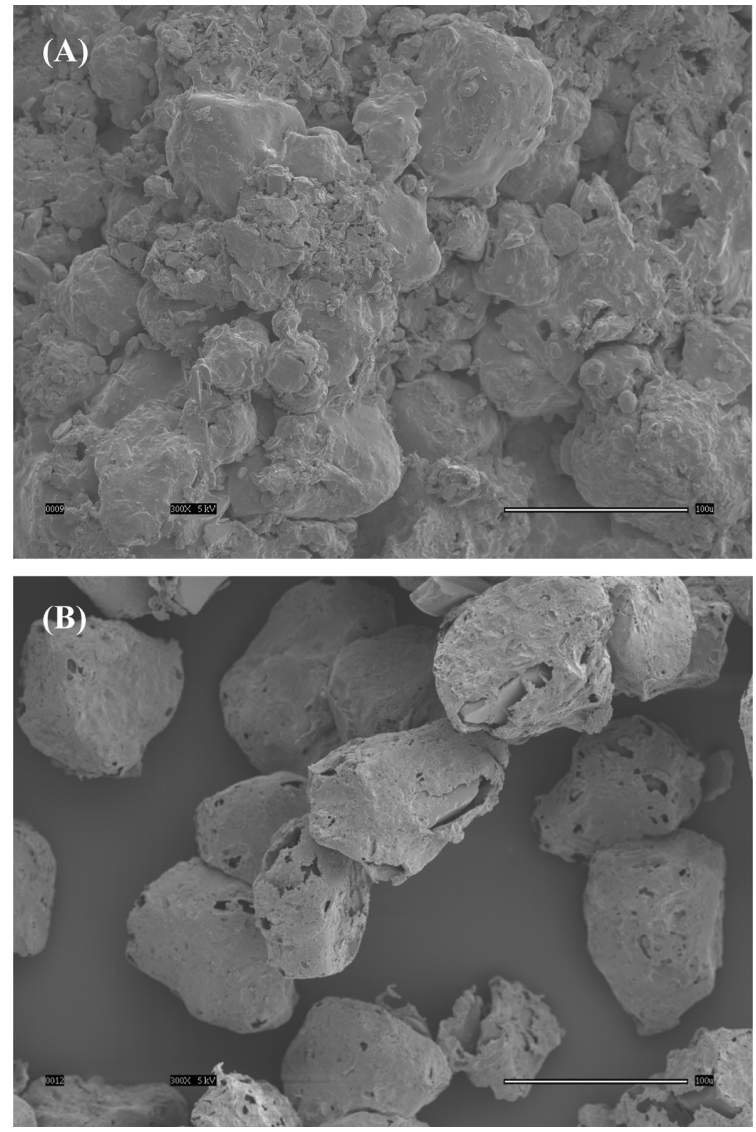

Figure 4. Scanning electron micrographs of the compressed tablet matrix containing Aquacoat ${ }^{\circledR}$ coated resin particles (A) and the coated resin particles after the dissolution test (B).

pressed tablet containing Aquacoat ${ }^{\circledR}$ coated resin particles. It could be easily observed that the coated resin particles are bigger than the tablet excipients in the formulation. They are surrounded by the smaller particles of the excipients. Moreover, the coated particles were collected after dissolution test and taken the SEM pictures. As shown in Figure 4 (B), coated particles of the compressed tablets showed very differently compared with those of uncompressed ones. Mechanical strength of EC coating is not so strong and EC film is not flexible either. Therefore, when compressed the surface of the coating became rough. This might cause the increased release rate as in Figure 3.

However, if the changes in release rate are consistent and reproducible even after the granulation and compression processes, it might be possible to make use of the formulation for the development of sustained release fast disintegrating tablets. As shown in Figure 5, four different batches of the tablets prepared in different days showed almost identical release rate $(n=3)$ and this might be promising one for the tablet development. 


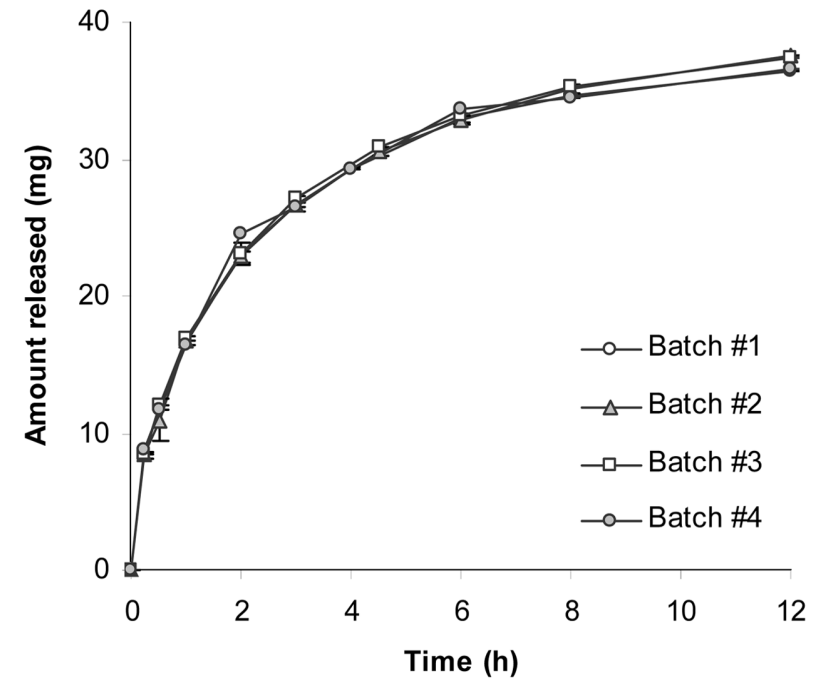

Figure 5. In-vitro release of DM from the four different batches of tablets in simulated gastric fluid $(\mathrm{pH}=1.2)$ at $37^{\circ} \mathrm{C}$.

\section{Surelease ${ }^{\circledR}$ coating}

As shown in Figure 6, granulation and compaction process affected drug release rate and the effect of granulation was more significant than that of the compression. Surelease ${ }^{\circledR}$ was more granulation sensitive than Aquacoat ${ }^{\circledR}$. Unlikely to Aquacoat $^{\circledR}$, there was little effect of compression, if any, for the Surelease ${ }^{\circledR}$ coated particles.

Figure 7 shows the SEM pictures of the Surelease ${ }^{\circledR}$ coated DM ion-exchange resin particles themselves $(20 \%$ coating level) and in granules after dissolution test. After granulation

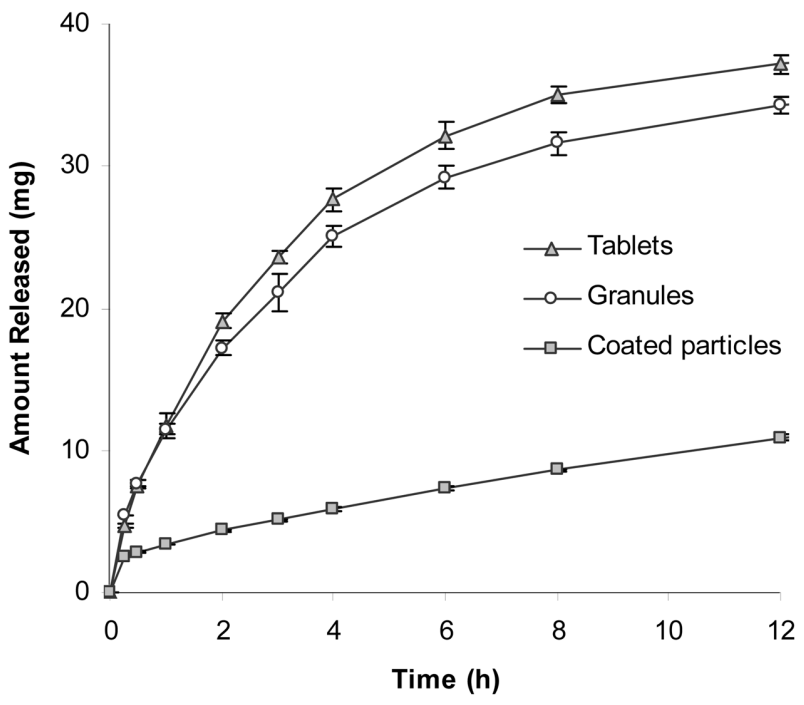

Figure 6. In-vitro release of DM from the Surelease ${ }^{\circledR}$ coated resin particles, and granules and tablets containing the coated resin particles in simulated gastric fluid $(\mathrm{pH}=1.2)$ at $37^{\circ} \mathrm{C}$. Granules and tablets have the same amount of coated particles to make the same amount of DM in each formulation.
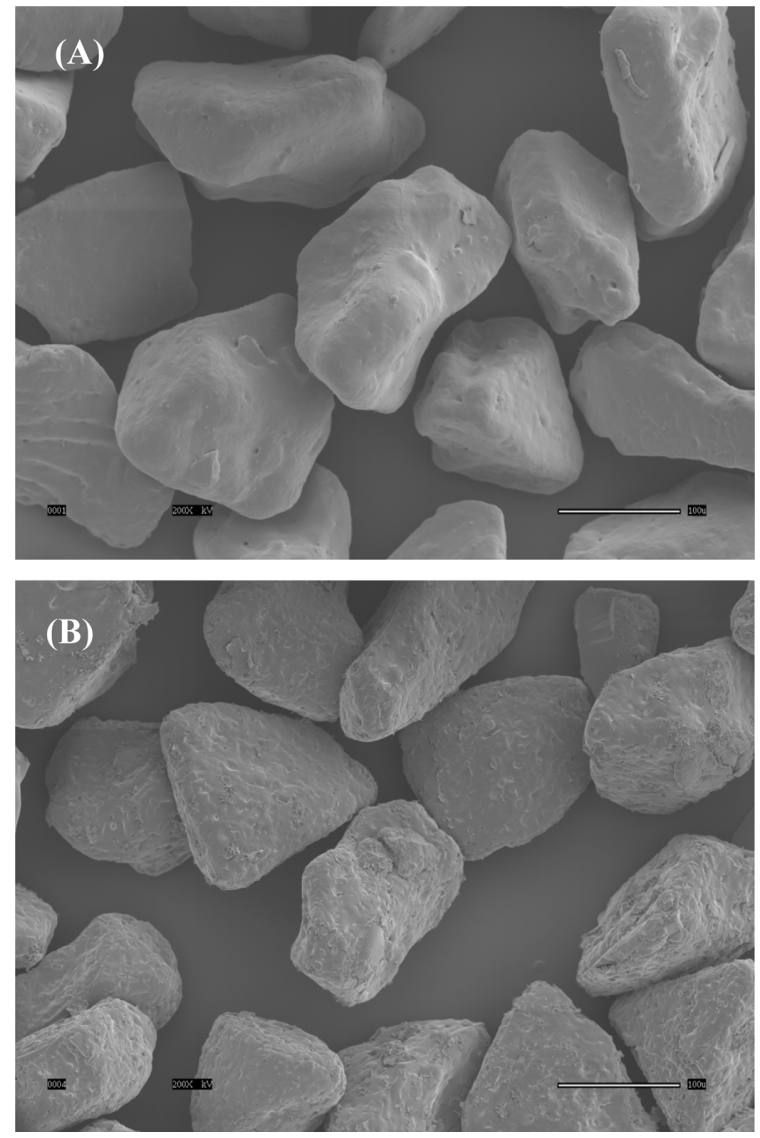

Figure 7. Scanning electron micrographs of Surelease ${ }^{\circledR}$ coated DM ion-exchange resin complex particles themselves (A) and in granules after dissolution test (B): (B) is from granules containing Surelease ${ }^{\circledR}$ coated particles.

(Figure 7-B), the coating film did not show good surface integrity compared to coated particle itself as shown Figure 7 (A), indicating that it might not be so resistant to granulation and/ or compression process. Mechanical strength of EC coating has been considered not so strong compared with acrylic and vinyl polymers. When compressed, the surface of the coating became rough and irregular and this might cause the increased release rate, too.

\section{Volume effect of release media on the drug release from ion-exchange resins}

One of the limitations of using ion-exchange resins as a drug carrier is that it has incomplete drug release due to the tightly crosslinked gel-type resins, leading to a significant tailing. During the dissolution test, the loaded drug molecules can be released by the ion-exchange reaction with counter ions $\left(\mathrm{H}^{+}\right.$in this study) in the dissolution medium. An important property of the ion-exchange reaction is that the competitive binding of one ion over another can happen. For example, ion-exchange 


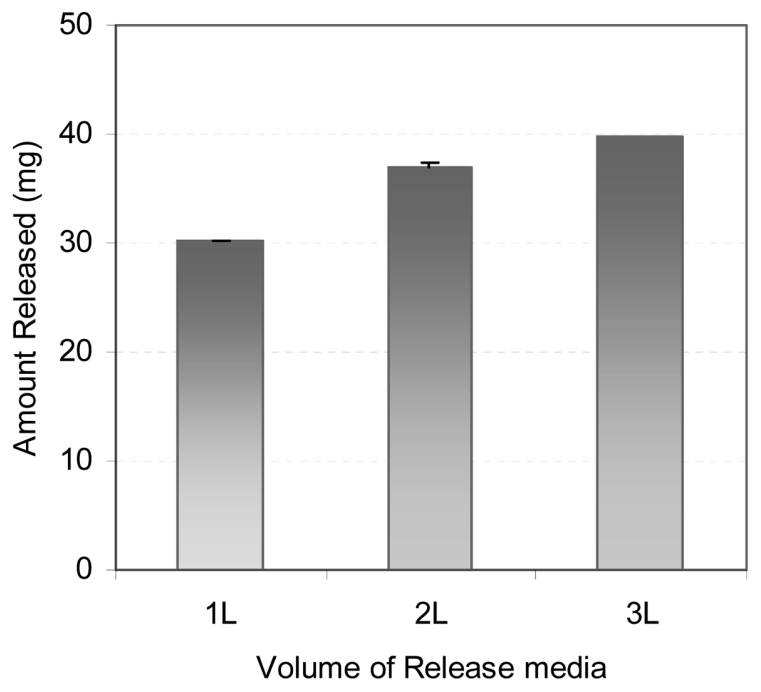

Figure 8. The amount of DM released after 24 hours from the DM ion-exchange resin complex in simulated gastric fluid $(\mathrm{pH}=1.2)$ at room temperature.

resin polymer preferentially binds with counter ion rather than ionic drug, or vice versa. This may help to predict and explain the affinity of ionic drugs to resins and ions in the surroundings, which is related to complex formation and drug release properties.

A significant tailing and incomplete drug release were observed as shown in the previous figures during the dissolution test. It was assumed that the number of counter ions remaining in the dissolution medium might be decreasing as time goes on and it would affect the amount of released drug. In order to investigate the effect of counter ions on the drug release, simple test as following was performed at room temperature. The concentration of $\mathrm{HCl}$ was kept constant to keep the ionic concentration same, which is recommended in USP. However, the volume of medium was increased up to 3 liters, so the amount of counter ions would be increased. Figure 8 shows the result of the test. As the volume increased up to $3 \mathrm{~L}$, the released amount increased more than $30 \%$ compared to that of $1 \mathrm{~L}$. In the previous dissolution tests, $0.9 \mathrm{~L}$ was used and the amount released was mostly between 30 and $40 \mathrm{mg}$. The lower released amount of $1 \mathrm{~L}$ might be due to the temperature on the release rate. If in vivo or flow-through diffusion tests are applied, the release rate might show differently.

\section{Conclusion}

Sustained release drug delivery system could be obtained using the resin complexes as core carriers for the aqueous polymeric coating with the Wurster process. EC based polymers were selected as the coating materials. Since the mechanical properties of $\mathrm{EC}$ were not resistant to granulation and compaction process, it might not be a good candidate. However, when tablets were prepared in different batches, the release profiles were almost identical and showed feasibility for the incorporation of the coated resin particles into the fast disintegrating tablet formulation. EC aqueous polymeric dispersions are still good candidates for the sustained release application of the tablet dosage forms.

\section{Acknowledgements}

This work was supported for two years by Pusan National University Research Grant.

\section{References}

Atyabi, F., Sharma, H.L., Mohammad, H.A.H., Fell, J.T., 1996. Controlled drug release from coated floating ion exchange resin beads. J. Control. Release 42, 25-28.

Bhaskar, R., Murthy, R.S.R., Miglani, B.D., Viswanathan, K., 1986. Novel Method to evaluate diffusion controlled release of drug from resinate. Int. J. Pharm. 28, 59-66.

Bodmeier, R., 1997. Tableting of coated pellets. Eur. J. Pharm. Biopharm. 43, 1-8.

Bodmeier, R., Paeratakul, O., 1997. Plasticizer uptake by aqueous colloidal polymer dispersions used for the coating of solid dosage forms. Int. J. Pharm. 152, 17-26.

Dashevsky, A., Kolter, K., Bodmeier, R., 2004. Compression of pellets coated with various aqueous polymer dispersions. Int. J. Pharm. 279, 19-26.

Fu, Y., Jeong, S.H., Park, K., 2005. Fast-melting tablets based on highly plastic granules. J. Control. Release 109, 203-210.

Ghebre-Sellassie, I., 1994. Multiparticulate oral drug delivery. ed., New York: Marcel Dekker, Inc.

Langer, D.L., 1993. Polymer-controlled drug delivery systems. Accounts Chem. Res. 26, 537-542.

Motycka, S., Nairn, J.G., 1978. Influence of wax coatings on release rate of anions from ion-exchange resin beads. J. Pharm. Sci. 67, 500-503.

Nagai, T., Obara, S., Kokubo, H., Hoshi, N., 1997. Application of HPMC and HPMCAS to aqueous film coating of pharmaceutical dosage forms. ed., New York: Marcel Dekker, Inc. pp. 177-225.

Wesseling, M., Bodmeier, R., 2001. Influence of plasticization time, curing conditions, storage time, and core properties on the drug release from Aquacoat-coated pellets. Pharm. Dev. Technol. 6, 325-331.

Wheatley, T.A., Steuernagel, C.R., 1997. Latex emulsions for controlled drug delivery. ed., New York: Marcel Dekker, Inc. pp. $1-54$. 